\title{
On the potential for observational equivalence in experiments on risky choice when a power value function is assumed
}

\author{
D.A. Peel* , Jie Zhang \\ University of Lancaster, Management Centre, Department of Economics, Lancaster LA1 4YX, United Kingdom
}

\section{A R T I C L E I N F O}

\section{Article history:}

Received 27 April 2011

Received in revised form

16 December 2011

Accepted 20 December 2011

Available online 31 December 2011

\section{JEL classification:}

C72

C92

D80

D84

Keywords:

Cumulative prospect theory

Power value function

Markowitz model

Expo-value utility function

Probability distortion

Lotteries

\begin{abstract}
A B S T R A C T
We demonstrate theoretically and illustrate the implications of assuming power utility when the true function is of the expo-power form. Empirical results can appear to be consistent with cumulative prospect theory when they are in fact generated from a Markowitz model.
\end{abstract}

Crown Copyright (c) 2011 Published by Elsevier B.V. All rights reserved.

\section{Introduction}

In numerous empirical studies of the efficacy of cumulative prospect theory (CPT) to fit experimental data, it has been assumed that the value function has the power form (see, for example, Camerer and Ho (1994), Scott (2006), Harrison et al. (2010)).

However, the assumption of a power value function conflicts with other important empirical evidence. For example, Holt and Laury (2002) examine agent choices between a sequence of safe and risky gambles when the probabilities are held fixed and the payoff size is varied. Increases in the payoff levels lead agents to switch their choice from 'risky' to 'safe' lotteries.

Holt and Laury (2002) report estimates of the expo-power value function which, unlike the power value function, allows agents to switch from a 'risky' to a 'safe' choice as the payoff size is increased. It also has the convenient property, as demonstrated by Abdellaoui et al. (2007), that it nests the power function and also the Markowitz (1952) model of non-expected utility.

\footnotetext{
* Corresponding author. Tel.: +44 0 1524593590; fax: +44 01524594244 .

E-mail address: d.peel@lancaster.ac.uk (D.A. Peel).
}

The purpose of this letter is to demonstrate theoretically and to illustrate with a simulated data set that estimates of CPT based on a power value function can appear to parsimoniously fit the data set when the true model is of the Markowitz (1952) form. We also report estimates based on a real data set, which suggest that this has some empirical validity.

In Section 2, we briefly set out the surely neglected Markowitz model and some experimental evidence that is consistent with it. In Section 3, we employ simulated data from the Markowitz model and illustrate how estimates based on a power value function can appear to provide empirical support for CPT. We also report estimates of the Markowitz model and a variety of mixture models employing the experimental data of Harrison et al. (2010). The final section offers a brief conclusion.

\section{The Markowitz model of utility}

Markowitz (1952) assumed that, from a customary or normal level of wealth (which is the reference point), agents' value functions are bounded and initially risk seeking then risk averse over gains, and initially risk adverse then risk seeking over losses. He also assumed that agents are loss averse in the sense later 
adopted by Kahneman and Tversky (1979). He writes, 'Generally, people avoid symmetric bets. This suggests that the curve falls faster to the left of the origin than it rises to the right. We may assume that $|U(-X)|>U(X), X>0$ where $X=0$ is customary wealth' (Markowitz, 1952, pp. 154-155). Markowitz only analyzed outcomes of risky choice when agents were assumed not to exhibit probability distortion. This was 'because we are concerned with a hypothesis about the utility function and do not want to get involved in questions concerning subjective probability beliefs' (Markowitz, 1952, p. 155). The Markowitz model embodying probability distortion is a generalization of CPT in which the agent is assumed risk averse over gains and risk seeking over losses, the value functions are not bounded, ${ }^{1}$ and agents are loss averse. There is considerable body of experimental evidence consistent with a Markowitz value function. (See, for example, Levy and Levy (2002), Pennings and Smidts (2003), Weber and Chapman (2005), BoschDomènech and Silvestre (2010).)

\section{The power value function and observational equivalence}

As first noted by Abdellaoui et al. (2007), a parametric specification that nests both the Markowitz and Tversky and Kahneman value functions can be based on the expo-power function of Saha (1993).

For simplicity, we only consider outcomes defined over gains $(G)$. In this case, the expo-power value function, $E u$, is given by

$E u=\frac{1-e^{-r G^{n}}}{r}$,

where $G$ is the gain and $r$ and $n$ are positive constants. With $n \leq 1$, the agent is risk averse over gains as hypothesized by Tversky and Kahneman. With $n>1$, we obtain the form of value function hypothesized by Markowitz. The agent is initially risk seeking, $\frac{n-1}{n r}>G^{n}$, then risk averse, $\frac{n-1}{n r}<G^{n}$. The expo-power utility function has the convenient property that it nests the power function as $r \rightarrow 0$ (by L'Hopital's Rule).

Employing the expo-power function, we illustrate how the assumption of power utility can lead to observationally equivalent results between the different models. We assume that an agent has a Markowitz value function with parameters $r=0.02^{2}$ and $n=1.1$. The agent is assumed not to exhibit probability distortion. Using experimental methods as in Abdellaoui (2000), the certainty equivalent (ce) values of the following two lotteries, $A$ and $B$, are elicited.

A: 0.05 probability of 50 and 0.95 probability of 0 , and

$B$ : 0.1 probability of 100 and 0.90 probability of 0 .

We assume that the certainty equivalents of lotteries $A$ and $B$ are calculated correctly as 1.85 and 4.35 , respectively. Values of the power exponent $(k)$ and the distortion parameter $(\delta)$ consistent with the elicited certainty equivalents are obtained from the relationship

$w(p) G^{k}=c e$,

where

$w(p)=\frac{p^{\delta}}{\left[p^{\delta}+(1-p)^{\delta}\right]^{\frac{1}{\delta}}}$

is the probability weighting function employed in many empirical studies, (e.g. Tversky and Kahneman (1992)), and where $p$ is the objective probability and $\delta$ is a constant.

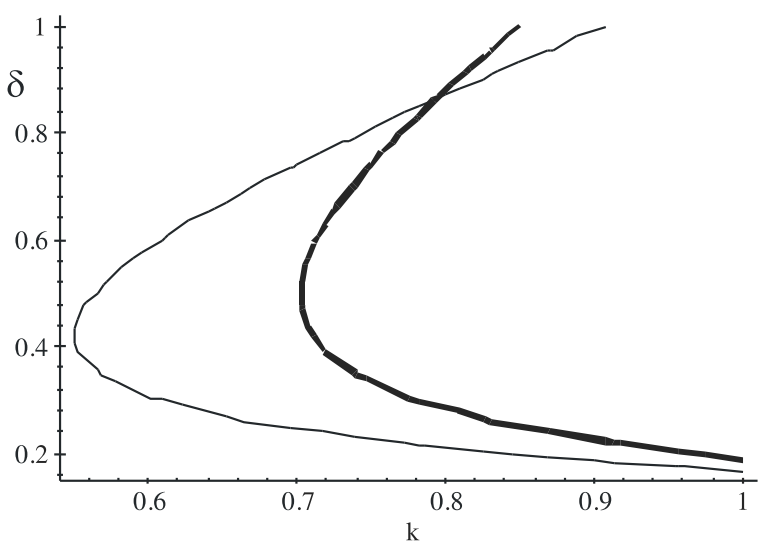

Fig. 1. Intersecting frontiers for certainty equivalents when power utility rather the correct expo-power utility is assumed.

In Fig. 1, we plot the $k$ and $\delta$ frontiers for the power exponents and the distortion parameters consistent with each elicited certainty equivalent value.

We observe that there are an infinite number of combinations of $k$ and $\delta$ which generate the elicited certainty equivalents of the two lotteries and, importantly, that the frontiers intersect. The intersection occurs in our example with a power exponent value of approximately $k=0.8$ and a distortion parameter value of approximately $\delta=0.85$. Consequently, a value of $k$, epsilon more than 0.8 or epsilon less than 0.85 would lead us to suppose, erroneously, that CPT is the appropriate model.

In order to test this hypothesis more formally, we assumed a Markowitz utility function with zero probability distortion and $r$ fixed at 0.02 . We varied $n$ randomly between 1.27 and 1.1 and generated 1000 utility certainty equivalents for lotteries employing probabilities between 0.0001 and 0.95 and payoffs between 0.1 and 320 . We fitted the power value function with the probability weighting function given by (3) to this simulated data. We obtained an estimate of the power exponent, $k=0.65$, and the probability distortion parameter, $\delta=0.62 .{ }^{3}$ For this simulated data set we would accept the CPT model even though this is not the case.

Clearly the estimated values of $k$ and $\delta$ will change as we change the probabilities, the payoffs, and the value of $r$ in the risky choice experiment. However, the estimates on simulated data reveal that $\mathrm{CPT}$ embodying a power value function may parsimoniously fit the data when the true model is of the Markowitz form.

To see if this has import in real data sets, we estimated the Markowitz model with probability distortion employing the data set of Harrison et al. (2010). Harrison et al. (2010) assumed a power value function. Again we assumed that the probability distortion was given by (3).

The Harrison et al. data set consists of 3717 observations of the responses of 531 subjects to 7 risky choice questions answered by poor agents in Ethiopia, India, and Uganda. An important feature of the Harrison et al. experiments is that the 'risky' choices involved large real payoffs that were $250 \%, 339 \%$, and $278 \%$ of daily wages. We employ this data set to determine whether the Markowitz

\footnotetext{
1 It is now recognised that the assumption that the value functions are bounded is necessary in applications of CPT in areas such as finance. See, for example, De Giorgi and Hens (2006).

2 We should note that Holt and Laury (2002) report a value of $r=0.029$.

3 We also obtained qualitatively the same result for another experiment based on the Markowitz specification involving two outcome gambles, or where the choice is between a risky lottery and a safe alternative. All data are available on request.
} 
Table 1

Estimation results for different models.

\begin{tabular}{|c|c|c|c|}
\hline & $\begin{array}{l}\text { Exhibit } 1 \\
\text { CPT }\end{array}$ & $\begin{array}{l}\text { Exhibit } 2 \\
\text { Expo-power } \\
\delta \neq 1\end{array}$ & $\begin{array}{l}\text { Exhibit } 3 \\
\text { Mixture model } \\
\text { Expo-power, } \delta=1,+\mathrm{CPT}\end{array}$ \\
\hline $\begin{array}{l}\text { Log pseudo- } \\
\text { likelihood }\end{array}$ & -7961 & -2455 & -2456 \\
\hline$r 1$ & & $\begin{array}{l}0.60 \\
(0.06)\end{array}$ & $\begin{array}{l}0.62 \\
(0.06)\end{array}$ \\
\hline$n 1$ & & $\begin{array}{l}1.96 \\
(. .)\end{array}$ & $\begin{array}{l}1.60 \\
(0.28)\end{array}$ \\
\hline$\delta 1$ & & $\begin{array}{l}1.25 \\
(0.08)\end{array}$ & \\
\hline$n 2$ & $\begin{array}{l}0.46 \\
(0.04)\end{array}$ & & $\begin{array}{l}0.53 \\
(. .)\end{array}$ \\
\hline$\delta 2$ & $\begin{array}{l}1.38 \\
(0.07)\end{array}$ & & $\begin{array}{l}1.73 \\
(0.007)\end{array}$ \\
\hline$p 1$ & & & $\begin{array}{l}0.06 \\
(0.02)\end{array}$ \\
\hline
\end{tabular}

The estimation is based on 3717 observations from Harrison et al. (2010). $p 1$ is the percentage of data explained by the power function in the mixture model. $n 1$ and $\delta 1$ are the exponent in the expo-power function and the distortion parameter associated with the expo-power; $n 2$ and $\delta 2$ are the parameters employing the power specification. Standard errors where convergence is obtained are in brackets.

model can help explain the responses. The estimated results were obtained using the STATA program of Harrison et al. (2010). Some salient empirical results are reported in Table 1.

Convergence of parameters was a problem in some specifications as also encountered by Harrison et al. (2010). However, the reported results are reasonably clear cut, and they illustrate that the Markowitz model, exhibit 2, has a better fit to the Harrison data than the power specification of CPT, exhibit 1 . In all cases the estimate of the exponent in the expo-power value function is significantly greater than unity. Estimates of the probability distortion parameters are greater than unity, which was also a feature of the results for CPT that Harrison et al. reported.

We also estimated some mixture models that for this data set reveal that a model that is a weighted average of the Markowitz model and CPT provides the best overall fit, though CPT only receives a $6.5 \%$ weight.

\section{Conclusions}

We demonstrated that assuming a power value function, when the true function is of the expo-power form, could lead to seriously misleading implications for the properties of the value function and the degree of probability distortion. In fact, CPT can appear to parsimoniously fit a data set when the true model is of the Markowitz form. Overall, our results lead us to suggest that in experimental work estimates of the expo-power function should be reported.

\section{References}

Abdellaoui, M., 2000. Parameter-free elicitation of utility and probability weighting functions. Management Science (November), 1497-1512.

Abdellaoui, M., Barrios, C., Wakker, P.P., 2007. Reconciling introspective utility with revealed preference: experimental arguments based on prospect theory. Journal of Econometrics (May), 356-378.

Bosch-Domènech, A., Silvestre, J., 2010. Averting risk in the face of large losses Bernoulli vs. Tversky and Kahneman. Economics Letters 107, 180-182.

Camerer, C., Ho, T.-H., 1994. Violations of betweenness axiom and nonlinearity in probability. Journal of Risk and Uncertainty 8, 167-196.

De Giorgi, E., Hens, T., 2006. Making prospect theory fit for finance. Financial Markets and Portfolio Management 20 (3), 339-360.

Harrison, G.W., Humphrey, S.J., Verschoor, A., 2010. Choice under uncertainty: evidence from Ethiopia, India and Uganda. The Economic Journal 120 (March) 80-104.

Holt, C.A., Laury, S.K., 2002. Risk aversion and incentive effects. American Economic Review 97, 1644-1655.

Kahneman, D., Tversky, A., 1979. Prospect theory: an analysis of decision under risk Econometrica 47 (2), 263-269.

Levy, H., Levy, M., 2002. Prospect theory, much ado about nothing? Management Science 48, 1334-1349.

Markowitz, H.M., 1952. The utility of wealth. Journal of Political Economy 56 151-154.

Pennings, J.M.E., Smidts, A., 2003. The shape of utility functions and organizational behavior. Management Science 49 (9), 1251-1263.

Saha, A., 1993. Expo-power utility: a flexible form for absolute and relative risk aversion. American Journal of Agricultural Economics 75, 905-913.

Scott, H.P., 2006. Cumulative prospect theory's functional menagerie. Journal of Risk and Uncertainty 3 (2), 101-130.

Tversky, A., Kahneman, D., 1992. Advances in prospect theory: cumulative representation of uncertainty. Journal of Risk and Uncertainty 5 (4), 297-323.

Weber, B.J., Chapman, G.B., 2005. Playing for peanuts: why is risk seeking more common for low-stakes gambles? Organizational Behavior and Human Decision Processes 97, 31-36. 